\title{
Cryorecanalization of an Obstructed Bronchial Stent in a 12-Year-Old Boy
}

\author{
J. Hetzel ${ }^{\mathrm{a}} \quad$ M. Kumpf ${ }^{\mathrm{b}} \quad$ M. Hetzel ${ }^{\mathrm{c}} \quad$ M. Hofbeck ${ }^{\mathrm{b}} \quad$ W. Baden ${ }^{\mathrm{b}}$ \\ ${ }^{a}$ Internal Medicine, and ${ }^{b}$ Department of Pediatric Cardiology and Pulmology, Children's Hospital, \\ University of Tübingen, and ${ }^{\mathrm{C}}$ Red Cross Hospital, Bad Cannstatt, Germany
}

\section{Established Facts}

- Stenting of the major airways is a therapeutic option for significant symptomatic bronchial stenosis.

- Stent obstruction by granulation tissue is the most frequent complication of this treatment in children.

\section{Novel Insights}

- Cryorecanalization is an interesting new therapeutic option for the treatment of severe stent obstruction in children.

- A miniaturized probe allows the application of this technique through flexible pediatric bronchoscopes.

\section{Key Words}

Children • Bronchial stent, obstruction, intervention • Cryorecanalization

\begin{abstract}
We report a 12-year-old boy who underwent stent implantation into the left main bronchus at the age of 9.5 years for palliation of severe bronchial stenosis. He had developed complete obstruction of the stent by granulation tissue resulting in respiratory deterioration and the requirement of mechanical ventilation. The stent obstruction was treated at the age of 11.5 years by cryorecanalization. In this technique, cooling of the tip of the cryoprobe is used to induce adherence of the obstructing tissue allowing the subsequent re-
\end{abstract}

moval of tissue particles by retraction of the probe. Under general anesthesia, a miniaturized cryoprobe was advanced via the working channel of a flexible bronchoscope. Repeat maneuvers of freezing and retraction resulted in complete recanalization of the stent. Repeat bronchoscopies 4 and 12 weeks later revealed recurrent formation of some granulation tissue which was removed by repeat cryorecanalization. Seven months after the initial procedure there was a complete patency of the stent. According to our experience, cryorecanalization is a safe and effective alternative for the treatment of stent obstruction by granulation tissue. Due to the introduction of a miniaturized probe, this method is well applicable in children since it can be performed via the working channel of a flexible pediatric bronchoscope.

Copyright $\odot 2011$ S. Karger AG, Basel

\section{KARGER}

Fax +4161306 1234

E-Mail karger@karger.ch

www.karger.com
(C) 2011 S. Karger AG, Basel

0025-7931/11/0823-0290\$38.00/0

Accessible online at:

www.karger.com/res
Dr. Winfried Baden

Children's Hospital, University of Tübingen

Hoppe-Seyler-Strasse 1, DE-72076 Tübingen (Germany)

Tel. +497071298 3812, Fax +497071295054

E-Mail winfried.baden@med.uni-tuebingen.de 


\section{Introduction}

Bronchial obstruction, although rare in infants and children, is associated with significant morbidity and mortality [1-7]. Stenting of the major airways is a therapeutic option for significant symptomatic bronchial stenosis. In children, however, it is frequently associated with the formation of granulation tissue causing a secondary obstruction of the stent.

In this report we describe the first successful treatment of stent obstruction by cryorecanalization with a new miniaturized probe in a child.

\section{Patient Presentation}

Our patient suffers from arthrogryposis multiplex congenita type III with joint ankylosis, spine deformation, and bilateral hip dislocation. He developed scoliosis and severe deformity of the chest resulting in a leftward malposition of the heart and subsequent compression of the left main bronchus. Progressive respiratory insufficiency required the creation of a tracheostoma at the age of 3 months and mechanical ventilation at night. At the age of 9 years, a silicone stent had to be implanted into the obstructed left main bronchus for the treatment of recurrent dystelectasis and chronic infections of the left lung. However, after 2 months the stent dislocated; it was removed and replaced by a covered nitinol stent (Ultraflex ${ }^{\circledR}, 40 \times 8 \mathrm{~mm}$ ). At the age of 11.5 years there was rapid respiratory deterioration with the requirement of continuous mechanical ventilation. Bronchoscopy revealed a subtotal obstruction of the left main bronchus by granulation tissue at the level of the proximal end of the stent (fig. 1). Possible therapeutic options included overstenting, pneumonectomy of the left lung, or cryorecanalization. Following discussion with the parents we decided on cryorecanalization. Balloon dilatation was not an option because the granulomatous tissue reached from the noncovered area of the stent into the covered area. Therefore, an extraction technique was necessary.

\section{Technique}

This technique uses a cryoprobe which is perfused by $\mathrm{N}_{2} \mathrm{O}$ in a closed probe circuit. Cooling of the probe tip to a temperature of $-89.5^{\circ} \mathrm{C}$ is achieved by rapid gas expansion when injected from a highly pressurized capillary channel into a cavum inside the probe tip, according to Joule Thompson's law. The gas flow through the probe is activated by a foot switch for intervals of up to $2 \mathrm{~s}$.

The intervention in our patient was performed under general anesthesia. Following the removal of the tracheal cannula a flexible videobronchoscope (Pentax EB1570K, outer diameter 5.1 $\mathrm{mm}$; Pentax Europe GmbH, Hamburg, Germany) was introduced via a nasotracheal tube into the left main bronchus. The flexible cryoprobe (ERBEKRYO CA ${ }^{\circledR}, 1.9 \mathrm{~mm}$ outer diameter, length 90 $\mathrm{cm}$; Erbe Medizintechnik GmbH, Tübingen, Germany) was advanced via the $2.0-\mathrm{mm}$ working channel of the bronchoscope (fig. 2). The effect and extension of the cryorecanalization was supervised via the bronchoscope and care was taken to avoid contact of the cryoprobe with the struts of the stent. Frozen particles of granulation tissue obstructing the lumen of the stent were gently removed by subsequent freezing and retraction maneuvers resulting in complete recanalization (fig. 3). Mild local bleeding was controlled by topic xylometazoline.

Repeat flexible bronchoscopy (Pentax EB1570K and Pentax FB15P, outer diameter $4.9 \mathrm{~mm}$, instrument channel $2.2 \mathrm{~mm}$ ) including repeat cryorecanalization had to be performed after 4 and 12 weeks with the removal of some recurrent granulomatous tissue. Bronchoscopy 7 months after the initial procedure revealed an excellent result with a widely patent stent in the left main bronchus (fig. 4).

\section{Discussion}

Although stent implantation is a well established therapy for the treatment of central airway obstruction in adults [2], there is only limited experience in the pediatric age group $[3,5,6]$. This is due to the fact that the indication for palliative stenting is much more frequent in adults due to the rarity of bronchial malignancies in children. Furthermore, bronchial and tracheal stenting for severe airway obstruction in children is considered only if there is no surgical alternative since the former treatment is associated with a significant number of severe disadvantages and complications [5]. These include an absent growth potential [4], interference with mucus clearance, dislocation of the stent, erosion of the bronchial wall, and stent obstruction by the formation of granulation tissue.

Stent obstruction by granulation tissue is a severe complication occurring in $9-18 \%$ of patients in the adult population $[1,2,4]$ and in $63 \%$ of the pediatric age group [6]. Some degree of granulation tissue formation is almost always present following stent implantation and presents a cobblestone appearance, protruding through the struts of the stent [3]. Granulomatous reactions seem to be less frequent with silicone stents as compared with metallic stents [8].

Therapeutic options for significant stent obstruction include repeat balloon dilatation [3], overstenting, and stent explantation, which is associated with significant morbidity and mortality [6] and which is almost impossible following the implantation of stainless steel wire stents like the PALMAZ ${ }^{\circledR}$ stent [9]. Further options include laser photoresection using Nd:Yag [10], carbon dioxide $\left(\mathrm{CO}_{2}\right)$ [11-13] laser, or argon plasma coagulation (APC) [14] therapy. Laser photoresection is well established in the treatment of obstructing bronchogenic carcinomas, bronchial adenomas, or postintubation tracheal 


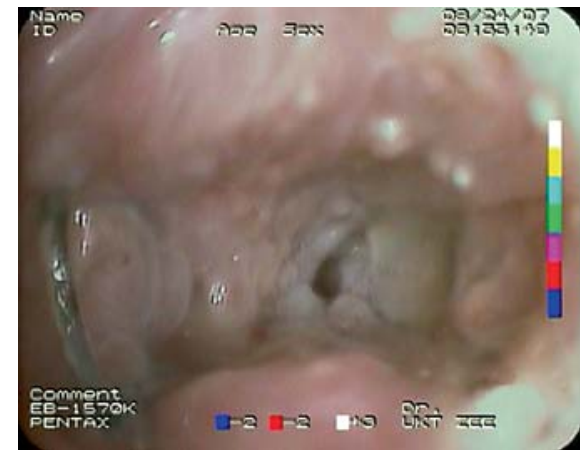

Fig. 1. Bronchoscopic view of the left main bronchus showing complete stent obstruction by granulation tissue.

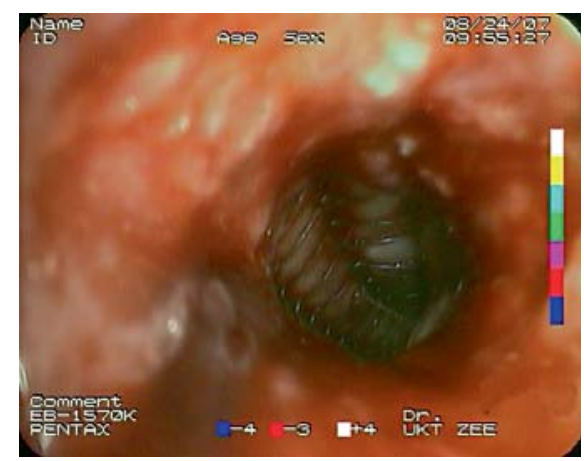

Fig. 3. Flexible videobronchoscopy following cryorecanalization shows the restored patency of the stent.

stenosis [10]. However, it requires very expensive equipment and an experienced examiner. Nd:YAG lasers have been replaced in many institutions by $\mathrm{CO}_{2}$ lasers since treatment with the latter is associated with less extensive tissue damage. APC therapy has less depth action and can provide excellent results for the recanalization of obstructed stents [14] as well as hemostasis during the procedure. Major risks of laser photoresection include wall perforation and stent destruction. Frequently, a combination of laser photoresection and balloon dilatation is needed to establish patent airways [10].

Cryorecanalization has been developed from a cryotherapy technique $[15,16]$ for the treatment of neoplastic tracheobronchial obstructions [15]. Cryotherapy induces selective cell necrosis due to cellular crystallization and local microthrombi [15]. However, since it requires rigid bronchoscopy its use is restricted to the major airways. In cryorecanalization, cooling of the probe tip is used to in-

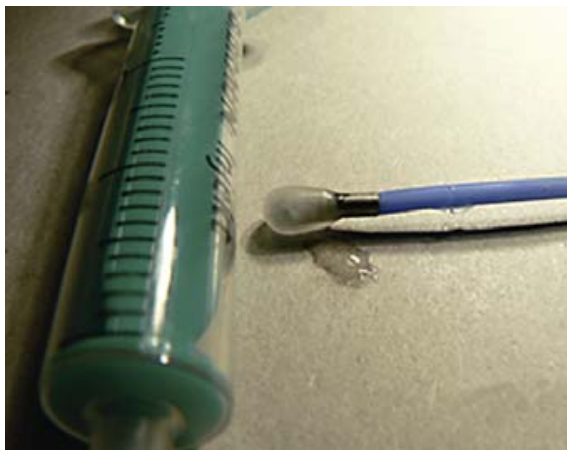

Fig. 2. Cryoprobe with a frozen tip in comparison to a 2-ml syringe.

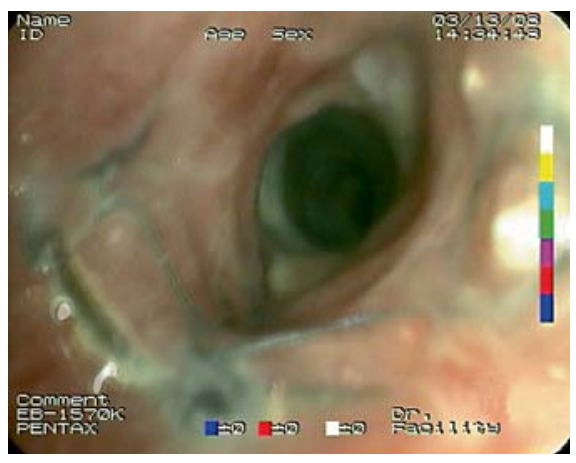

Fig. 4. The good result is maintained at follow-up after 7 months.

duce the adherence of obstructing tissue and to allow its removal by retraction of the probe together with the bronchoscope, thus leaving no necrosis at the intervention site and supplying excellent results in $83 \%$ of procedures in adult patients. The development of a thin and flexible cryoprobe (1.9-mm outer diameter) has revolutionized cryotherapy as it can be passed through a pediatric flexible fiber-optic bronchoscope $[15,16]$. Compared to laser therapy, cryorecanalization equipment is much cheaper and handling is safer for the operator and the team since it does not necessitate special protection as is required for laser therapy. In contrast to other thermic interventions, there is no need for $\mathrm{FiO}_{2}$ reduction. So far, no data on bleeding complications using cryorecanalization in children have been published. However, there are experiences in adults. In a series of 60 adult patients, mainly with endobronchial malignancies, 54 patients exhibited light bleeding which stopped spontaneously with- 
in a couple of minutes. Six patients had moderate bleeding which could be controlled with suction and was stopped in all patients by using an argon plasma beamer in flexible bronchoscopy. No fatal events occurred. Another concern of recanalization techniques is perforation. Cryorecanalization allows excellent control of the extension of the effect. This is mainly due to the fact that the 'ice front', which resembles the depth of the effect, can be exactly monitored during the recanalization procedure. Additionally, comparable to laser technology, cryorecanalization allows the focusing of the effect precisely on a distinct area. It therefore allows the treatment of lesions in all parts of the airways that can be reached with flexible bronchoscopes. In adults, it can be performed under local anesthesia and in outpatients.

Nitinol is characterized by a temperature-dependent shape memory. However, different compositions of the alloy result in different temperature thresholds. The stent type (UltraflexH; Boston Scientific) used in this patient changes its shape at a temperature of $500^{\circ} \mathrm{C}$. Therefore, no change in the stent's shape occurs by cooling.
Finally, the removed tissue shows excellent histologic quality $[17,18]$. This may be relevant in cases with the need to differentiate between granulomatous tissue and malignancies.

\section{Conclusion}

Stent obstruction by granulation tissue is the most frequent complication of this treatment in children, occurring in $63 \%$ of patients $[19,20]$. According to our experience, cryorecanalization is an interesting new therapeutic option for the treatment of severe stent obstruction in children.

A miniaturized probe allows the application of this technique through flexible bronchoscopes with an outer diameter of 4.9-5.1 $\mathrm{mm}$.

\section{Financial Disclosure and Conflicts of Interest}

None of the authors has stated a conflict of interest or received financial support for this publication.

\section{References}

1 Shin JH, Song HY, Ko GY, Shim TS, Kim SW, Cho YK, Ko HK, Kim YJ, Yoon HK, Sung KB: Treatment of tracheobronchial obstruction with a polytetrafluoroethylene-covered retrievable expandable nitinol stent. J Vasc Interv Radiol 2006; 17:657-663.

-2 Cosano PA, Munoz CL, Cosano Povedano FJ, Rubio SJ, Pascual MN, Escribano DA: Endoscopic treatment of central airway stenosis: five years' experience (in Spanish). Arch Bronconeumol 2005;41:322-327.

3 McLaren CA, Elliott MJ, Roebuck DJ: Tracheobronchial intervention in children. Eur J Radiol 2005;53:22-34.

4 Wells WJ, Hussain NS, Wood JC: Stenting of the mainstem bronchus in children: a word of caution. Ann Thorac Surg 2004;77:14201422.

5 Nicolai T, Huber RM, Reiter K, Merkenschlager A, Hautmann H, Mantel K: Metal airway stent implantation in children: follow-up of seven children. Pediatr Pulmonol 2001;31:289-296.

-6 Filler RM, Forte V, Chait P: Tracheobronchial stenting for the treatment of airway obstruction. J Pediatr Surg 1998;33:304-311.

-7 Baden W, Schaefer J, Kumpf M, Tzaribachev N, Pantalitschka T, Koitschev A, Ziemer G, Fuchs J, Hofbeck M: Comparison of imaging techniques in the diagnosis of bridging bronchus. Eur Respir J 2008;31:1125-1131.
8 Fayon M, Donato L, de Blic J, Labbe A, Becmeur F, Mely L, Dutau H: French experience of silicone tracheobronchial stenting in children. Pediatr Pulmonol 2005;39:21-27.

-9 Jacobs JP, Quintessenza JA, Botero LM, van Gelder HM, Giroud JM, Elliott MJ, Herberhold C: The role of airway stents in the management of pediatric tracheal, carinal, and bronchial disease. Eur J Cardiothorac Surg 2000;18:505-512.

-10 Dumon JF, Reboud E, Garbe L, Aucomte F, Meric B: Treatment of tracheobronchial lesions by laser photoresection. Chest 1982;81: 278-284.

11 Shapshay SM, Davis RK, Vaughan CW, Norton M, Strong MS, Simpson GT: Palliation of airway obstruction from tracheobronchial malignancy: use of the $\mathrm{CO}_{2}$ laser bronchoscope. Otolaryngol Head Neck Surg 1983;91: 615-619.

12 Oswal V, Flood LM, Ruckley RW: Use of bronchoscopic $\mathrm{CO}_{2}$ laser in palliation of obstruction tracheobronchial malignancy. J Laryngol Otol 1988;102:159-162.

13 Sipila J, Pulkkinen J, Hujala K, Grenman R: Endoscopic lasersurgery in obstructive tracheal and bronchial tumors: an update. Otolaryngol Pol 2004;58:187-190.
14 Reichle G, Freitag L, Kullmann HJ, Prenzel R, Macha HN, Farin G: Argon plasma coagulation in bronchology: a new method-alternative or complementary? (in German). Pneumologie 2000;54:508-516.

15 Mathur PN, Wolf KM, Busk MF, Briete WM, Datzman M: Fiberoptic bronchoscopic cryotherapy in the management of tracheobronchial obstruction. Chest 1996;110:718-723.

16 Hetzel M, Hetzel J, Schumann C, Marx N, Babiak A: Cryorecanalization: a new approach for the immediate management of acute airway obstruction. J Thorac Cardiovasc Surg 2004;127:1427-1431.

17 Babiak A, Hetzel J, Krishna G, Fritz P, Moeller P, Balli T, Hetzel M: Transbronchial cryobiopsy: a new tool for lung biopsies. Respiration 2009;78:203-208.

- 18 Hetzel J, Hetzel M, Hasel C, Moeller P, Babiak A: Old meets modern: the use of traditional cryoprobes in the age of molecular biology. Respiration 2008;76:193-197.

19 Filler RM, Forte V, Fraga JC, Matute J: The use of expandable metallic airway stents for tracheobronchial obstruction in children. J Pediatr Surg 1995;30:1050-1055.

-20 Furman RH, Backer CL, Dunham ME, Donaldson J, Mavroudis C, Holinger LD: The use of balloon-expandable metallic stents in the treatment of pediatric tracheomalacia and bronchomalacia. Arch Otolaryngol Head Neck Surg 1999;125:203-207. 